\title{
DOUTRINA
}

\section{REPERCUSSÕES DA EMENDA CONSTITUCIONAL № 19 SOBRE O REGIME JURÍDICO DAS LICITAÇÕES}

\author{
JESSÉ TORRES PEREIRA JUNIOR*
}

\begin{abstract}
A Emenda Constitucional $\mathrm{n}^{\mathrm{9}} 19$, publicada no DOU de 05.06 .98 , pretendeu promover o que se convencionou chamar de reforma administrativa do Estado. A Constituição da República de 1988 conferiu, às licitações da Administração Pública, pela primeira vez na história das Cartas Políticas Fundamentais brasileiras, o status de tema constitucional, tal a importância que o princípio da competitividade no acesso às contratações administrativas passou a ter para a democratização e a moralidade da gestão pública, sem prejuízo da segurança jurídica, no Estado contemporâneo.

Natural, portanto, que a Emenda da Reforma Administrativa dedicasse atenção à matéria, introduzindo inovações tendentes ao aperfeiçoamento dos certames seletivos para a contratação de compras, obras, serviços e alienações. A Emenda introduziu modificações que alcançam as licitações nos arts. 22, XXVII, e 173. O sentido e o alcance dessas modificações é o objeto dos comentários que se seguem.

"Art. 22. Compete privativamente à União legislar sobre:
\end{abstract}

XXVII - normas gerais de licitação e contratação, em todas as modalidades, para as administrações públicas diretas, autárquicas e fundacionais da União, Estados, Distrito Federal e Municípios, obedecido o disposto no art. 37, XXI, e para as empresas públicas e sociedades de economia mista, nos termos do art. 173, $\S l^{\mathscr{0}}, I I I$;

Um dos objetivos nucleares da reforma intentada pela Emenda 19 aparece nas entrelinhas das modificações que introduz nos arts. 22, XXVII, 37, XIX e parágrafos, e 173. A revisão das funções administrativas do Estado concentra atenção no papel que este passou a desempenhar, no Brasil, por três décadas, a partir dos anos 60 ,

* Juiz de Direito de Entrância Especial e Conferencista de Direito Administrativo na Escola da Magistratura do Estado do Rio de Janeiro. Colaborador da Enciclopédia Saraiva do Direito. Membro do Instituto Brasileiro de Direito Constitucional e do Instituto Brasileiro de Direito Administrativo. Autor dos "Comentários à Lei das Licitações e Contrataçōes da Administração Pública" (Ed. Renovar, 4a edição). 
com grande destaque para atividades de prestação de serviços e de fomento econômico, que identificam o Estado desse período como empresário e comerciante, cujos instrumentos foram as empresas públicas e sociedades de economia mista, criadas às centenas, mediante leis genéricas e atos de administração, pela União, pelos Estados-membros e pelos Municípios de maior porte.

A Constituição de 1988 percebeu abusos na criação dessas empresas, tanto que passou a fazê-la depender de lei específica (art. 37, XIX). A percepção foi parcial; a reação aos abusos, insuficiente. Estes já haviam gerado deformações muito mais amplas, tanto na ordem jurídico-administrativa do Estado quanto na ordem econômica, com reflexos perversos sobre a aptidão da sociedade para desenvolver-se de modo equilibrado e auto-sustentável.

Do mesmo modo que a concepção dessas entidades de administração estatal indireta correspondeu a fenômeno mundial, também suas deformações ocorreram em escala internacional. O pós-guerra fez germinar a idéia de Estado do Bem-Estar, meio-termo entre o Estado de direito liberal (em que prevalecia o individualismo) e o Estado socialista (enfatizando o coletivo), que carecia de instrumentos supostamente ágeis e flexíveis para intervir na ordem econômico-social, suprindo as incapacidades da iniciativa privada. Esses instrumentos - modelos adaptados das sociedades comerciais privadas - foram as empresas públicas e sociedades de economia mista, cujo capital provinha, em sua maioria ou integralidade, do Estado, que também as controlava e geria, constituindo, a princípio, mecanismo eficaz para promover o desenvolvimento econômico e a justiça social.

O Estado não foi bem-sucedido empresário na maioria dos casos. As dificuldades começaram a ser notadas por toda parte. Na vizinha Argentina, o setor público econômico respondia, em 1975, por cerca de um terço do Produto Interno Bruto. "Es allí cuando comienzan a evidenciarse los males de la empresa estatal: déficit, falta de rentabilidad, decadencia tecnológica, ineficacia e ineficiencia en los servicios, altos costos operativos. Esta situación se profundiza y acelera con los años, produciendo la descapitalización creciente de la economía, el achicamiento del aparato productivo, la obsolescencia tecnológica y el creciente deterioro del nivel y calidad de vida.

“ ¿Se ha agotado el Estado? No como orden político de la sociedad. Sí como empresa estatal, como instrumento de crecimiento y de distribución. Y se ha agotado porque absorbió la capacidad de iniciativa, de creatividad, de participación y de responsabilidad del individuo y de las organizaciones sociales. Se agotó la empresa estatal hasta destruirse, porque se protegió detrás de sus prerrogativas, de precios políticos, de eximiciones impositivas, de gastos subsidiados por el tesoro nacional, de incrementos irracionales de personal, de estructuras administrativas obsoletas y de prestaciones injustas e ineficientes.

"Esta conducta estatal también se proyectó a la empresa privada hasta llegar a esterilizarla, a neutralizar sus notas esenciales, riesgo, competitividad, rentabilidad, eficacia, porque la protegió tras una maraña de subsidios que nunca cesaron, de préstamos baratos que jamás se reintegraron, de bienes regalados por el Estado.

"El paternalismo estatal generó un empresariado minusválido, por un lado. y un especulador empresario, por el otro. El Estado no há fracasado. Lo que ha 
fracasado es el estatismo. Ha fracasado la empresa pública protegida y la empresa privada subsidiada" (DROMI, Roberto, et alii, Reforma del Estado y Transformación Nacional. Ed. Ciencias de la Administración S.R.L., pags.110-111. Buenos Aires, 1990).

Parecem universais os sintomas revelados pela experiência platina no começo desta década, porquanto reproduzem quadros assemelhados onde quer que se tenha exagerado, como no Brasil, a crença de que as empresas para-estatais seriam a mola propulsora definitiva do desenvolvimento econômico. Tiveram, e ainda têm, papel importante, mas certamente não traduzem a solução definitiva para as desigualdades sociais, nem, em verdade, tal objetivo é prioritário, sob a perspectiva empresarial.

A Emenda 19 propõe as bases de uma revisão sobre o regime de atuação das empresas públicas e sociedades de economia mista na administração estatal indireta brasileira. O primeiro reparo que talvez conviesse oferecer à tentativa é a do risco de que, aprofundando sua intromissão em matéria tão sujeita a oscilações, sobre as quais há mais dúvidas do que certezas, a Emenda venha a acrescentar outro aos muitos apelidos com que se tentou popularizar a Constituição de 1988 - a "Constituição-laboratório", em temas administrativos.

$\mathrm{O}$ art. 22 da Constituição de 1988 estabelece as competências legislativas privativas da União. O inciso XXVII, em sua redação original, reservava-lhe a produção de normas gerais acerca de licitações e contratações, cogentes para toda a administração pública brasileira, direta e indireta, incluindo fundações e empresas sob controle governamental. Ou seja, nenhum órgão subordinado (despersonalizado) ou entidade vinculada (autarquias, fundações, empresas públicas e sociedades de economia mista, cada qual com personalidade jurídica própria, inconfundível com a personalidade dos entes públicos a que respectivamente vinculadas), de qualquer dos Poderes da União, dos Estados-membros, do Distrito e dos Municípios, estava desonerado da observância dessas normas gerais de edição privativa da União.

A Emenda 19 veio distinguir o que antes era comum a esses órgãos e entidades: de um lado, os ógãos subordinados da administração direta, bem como as autarquias e fundações vinculadas de sua administração indireta, continuam sujeitos às normas gerais veiculadas por lei federal, de abrangência nacional, em matéria de licitações e contratos; de outro, as empresas públicas e as sociedades de economia mista observarão estatuto jurídico próprio, que lei federal estabelecerá, e cujas normas acerca de licitações e contratos cumprirão os princípios da administração pública, porém desobrigadas da adoção das normas gerais impositivas para os órgãos da administração direta, autárquica e fundacional. É o que se extrai do articuladamente disposto nos arts. 22, XXVII, e 173, § 1², III, com as alterações da Emenda 19.

Em síntese, o novo regime:

(a) exclui da incidência das normas gerais referidas no art. 22, XXVII, as entidades de administração indireta que não as autarquias e fundações, ou seja, as empresas públicas e sociedades de economia mista, mantendo-as submissas apenas aos princípios que informam as licitações e contratações da administração pública;

(b) nos parágrafos do art. 173, autoriza que lei venha a estabelecer "o estatuto 
jurídico da empresa pública, da sociedade de economia mista e de suas subsidiárias que explorem atividade econômica de produção ou comercialização de bens ou de prestação de serviços";

(c) dita lei disporá, também, sobre "licitação e contratação de obras, serviços, compras e alienações, observados os princípios da administração pública".

As consequiências desde logo perceptíveis são:

(a) a legislação federal sobre normas gerais não mais disciplinará as licitações e contratações de obras, serviços, compras e alienações das empresas públicas e sociedades de economia mista, e suas subsidiárias, quer explorem atividade econômica, quer prestem serviços públicos, afastando-se a distinção, para esse fim, que antes se vislumbrava entre as entidades referidas nos arts. 173 e 175 da CF/88 (empresas e sociedades para-estatais que explorassem atividade econômica, e empresas e sociedades para-estatais que prestassem serviços públicos);

(b) a atividade contratual dessas entidades continuará sujeita aos princípios que, na administração direta, autárquica e fundacional, presidem as licitações e contratações; todavia, as normas implementadoras desses princípios serão aquelas que o estatuto jurídico dessas entidades estabelecerá, mediante lei específica;

(c) dito estatuto poderá:

I - divergir das normas regentes das licitações e contratações da administração direta. autárquica e fundacional, posto que as empresas não mais se sujeitam às normas gerais sobre a matéria;

II - simplificar procedimentos e ritos do processo licitatório, inclusive suprimindo ou invertendo fases, desde que respeitados os princípios da igualdade, da competitividade, do devido processo legal, da ampla defesa e do contraditório, entre outros de sede constitucional;

III - autorizar que as entidades editem seus regulamentos internos complementares das normas estatutárias, acerca de licitações e contratos, com o fim de atender aos objetivos societários da empresa, ou, ao contrário, proibir que os editem;

IV - traçar as regras a serem observadas no exercício dos controles interno e externo das licitações e contratações dessas entidades;

$\mathrm{V}$ - definir as sanções a que estarão sujeitos os gestores dessas empresas, por descumprimento das normas estatutárias concernentes às licitações e contratações.

A questão não é nova em nosso direito público. Em sua evolução histórica, na segunda metade deste século, sempre deu causa a dissensos, em sede de controle administrativo ou judicial. Sob o regime do Dec.-lei $n^{0} 200 / 67$, que inaugurou, na ordem jurídica positiva brasileira, a estrutura de administração direta e indireta, discutiu-se sobre a sujeição das empresas públicas e sociedades de economia mista ao dever de licitar para contratar, prevalecendo o entendimento de que se submetiam ao princípio da licitação, mas não às normas do decreto-lei, porquanto eram dotadas de personalidade jurídica de direito privado e deviam atuar como empresas privadas (Súmula 158. do Tribunal de Contas da União).

Sob o regime do Dec.-lei $n^{\circ} 2.300 / 86$, que se auto denominou de estatuto jurídico das licitações e contratos da administração pública brasileira, formulou-se a tese de 
que somente as empresas públicas e sociedades de economia mista prestadoras de serviços públicos estavam obrigadas a licitar e contratar segundo suas normas, tese que resultou vencida em face da $\mathrm{CF} / 88$, que tratou indistintamente as chamadas "estatais" exploradoras de atividade econômica ou prestadoras de serviços públicos.

A Emenda 19 ressuscita a controvérsia, para dirimi-la em favor da tese antes vencida, isto é, essas entidades devem obediência aos princípios administrativos da licitação, mas não às normas gerais federais existentes na matéria. A novidade é que, agora, a Constituição encampa a tese e remete para um futuro estatuto jurídico das empresas públicas e sociedades de economia mista a incumbência de definir as normas implementadoras daqueles princípios.

O fundamento da escolha parece guardar correlação com o sombrio diagnóstico sobre as deformações geradas por essas entidades, desde que introduzidas, na administração pública brasileira, pelo Dec.-lei $n^{2} 200 / 67$. Se, atreladas ao regime jurídico da administração pública em geral, as empresas públicas e sociedades de economia mista perdem competitividade e mostram-se ineficientes, deficitárias e defasadas em termos tecnológicos, a Emenda presume que, sujeitas a estatuto jurídico diferenciado, possam licitar e contratar com a fluência necessária para superar a distância que as separa da economia de mercado e de seus desafios de eficiência e eficácia.

Nada parece inequívoco nesse campo. Quando de seu surgimento, as empresas públicas e sociedades de economia mista eram saudadas como o ovo de Colombo da modernização do Estado. Agora, são apontadas como paradigmas de obsolescência. $\mathrm{O}$ anunciado estatuto jurídico dessas empresas terá o condão de, por si só, transformar o quadro? A experiência do direito administrativo fortemente recomenda prudência.

Melhor teria sido que não se trouxesse para a Constituição - que aspira perenidade e estabilidade - o ensaio de desenhar o perfil (que seria conclusivo exatamente por ser constitucional) de matéria sujeita a conceitos em permanente mutação, porquanto fenômeno também cultural, com matizes nacionais, regionais e locais diversificados. Sobretudo em momento de profundas modificações da ordem econômica, mercê do fenômeno, aparentemente irreversível, da globalização.

Acentua-se o sabor de "Constituição-laboratório" diante da aparente contradição entre o livramento dessas empresas das peias do controle das funções administrativas do Estado e a exigência, cada vez maior, de que esses controles ganhem em efetividade, o que também é alvo da Emenda 19. A elaboração e a promulgação da lei instituidora do estatuto jurídico dessas empresas, prometida no art. 173 emendado, porão à prova a convivência entre os princípios regentes da atividade empresarial privada (entre os quais o do lucro) e os princípios inscritos no art. 37, caput, da Constituição, em face dos quais o lucro, para citar apenas o ponto mais sensivel do confronto, deve refletir a rentabilidade da empresa, geradora de superávits que devem ser reaplicados na própria empresa, se pública é a função que exerce, ainda que de direito privado seja a natureza de sua personalidade jurídica.

Art. 22. $O \& J^{0}$ do art. 173 da Constituição Federal passa a vigorar com a seguinte redação:

"Art. 173

$\S l^{Q}$ A lei estabelecerá o estatuto jurídico da empresa pública, da sociedade de 
economia mista e de suas subsidiárias que explorem atividade econômica de produção ou comercialização de bens ou de prestação de serviços, dispondo sobre:

I - sua função social e formas de fiscalização pelo Estado e pela sociedade;

II - a sujeição ao regime jurídico próprio das empresas privadas, inclusive quanto aos direitos e obrigações civis, comerciais, trabalhistas e tributários;

III - licitação e contratação de obras, serviços, compras e alienações, observados os princípios da administração pública;

IV - a constituição e o funcionamento dos conselhos de administração e fiscal, com a participação de acionistas minoritários;

$V$ - os mandatos, a avaliação de desempenho e a responsabilidade dos administradores.

O art. 18 da Constituição consagra a autonomia dos entes federativos - União, Estados. Distrito Federal e Municípios. Na idéia de autonomia cabe a aptidão para dispor sobre a organização e a gestão dos próprios serviços e servidores, desde que observados os princípios e diretrizes gerais definidos na Constituição da República, que não é apenas federal, mas nacional. Não cabem nessa autonomia as idéias de independência, (incompatível com a "união indissolúvel" afirmada no art. $1^{1}$ ), e de hierarquia entre normas federais, estaduais, distritais e municipais, que cede à da competência (dever de agir em sua respectiva esfera de cometimento constitucional).

É inconciliável com a Constituição de 1988 a existência de norma de direito administrativo federal que se pretendesse provida de cogência nacional, tanto que não se aninhou o direito administrativo entre as matérias da competência legislativa privativa da União (art. 22, I).

Exercita-se a autonomia para organizar e gerir. Não há independência para separar-se da Federação, nem para dispor contrariamente ao Documento Fundamental da República Federativa.

Por isto, os casos de reserva legal que autorizam a intromissão da União na autonomia dos demais entes federativos são exceções que somente a própria Constituição pode estabelecer. $\mathrm{O}$ aludido art. 22 admite exceções, de sorte a reservar para a União competência para legislar sobre matéria administrativa, cuja execução inclui-se, em princípio, no cotidiano dos Estados e Municípios - desapropriação, requisição, normas gerais de licitações e contratos (incisos II, III e XXVII).

A Emenda 19 estabelece nova exceção de competência legislativa da União em matéria administrativa cuja execução cabe na autonomia dos entes federativos: o estatuto jurídico das empresas públicas e sociedades de economia mista. Não parece razoável supor que pudesse ser local a lei referida na nova redação dada ao $\S 1^{0}$ do art. 173, sob pena de comprometer-se o empenho da Emenda para livrar essas empresas das normas gerais sobre licitaçōes e contratos. Sendo estas normas, como são, da competência privativa da União, somente outra norma, igualmente geral e da competência privativa da União, poderia afastar a incidência daquelas.

O termo "estatuto" encerra conteúdo específico no jargão jurídico. Exprime disciplina completa dos direitos, deveres e obrigações de que são titulares todos os que ingressem em sua moldura de alcance normativo. Ao fazer uso da expressão "estatuto jurídico", a Emenda 19 quer realçar que a constituição, a estrutura interna, 
os objetivos sociais, o desempenho funcional, o regime dos direitos e obrigações que venham a contratar, bem assim a responsabilidade de seus administradores, estarão disciplinados num só conjunto orgânico de normas, a que deverão obediência todas as empresas públicas e sociedades de economia mista que existam ou venham a existir na administração pública brasileira, seja qual for o quadrante de sua atuação.

Do rol de matérias sobre as quais o estatuto disporá, indicadas nos incisos do $\S 1^{\mathfrak{Q}}$, estão ausentes apenas aquelas de que já cuidam as leis conformadoras de cada modelo societário conhecido no direito brasileiro. Assim, não caberá ao estatuto jurídico das empresas públicas e sociedades de economia mista ditar normas sobre o que é ou como deve operar uma sociedade por cotas ou uma sociedade anônima, sendo estes os modelos societários que determinada entidade venha a adotar ao ser constituída, porquanto já são objeto de legislação específica.

Todavia, cabendo ao estatuto, como declarado no inciso I, dispor sobre a função social e formas de fiscalização da empresa pelo Estado e pela sociedade, não seria de afastar-se a possibilidade de vir a traçar normas especiais que ajustem os modelos societários do direito comercial às peculiaridades daquelas função e formas de fiscalização, que não serão as mesmas de um empreendimento comercial privado.

Tanto que o inciso IV alude, ademais, à participação de acionistas minoritários no funcionamento dos conselhos de administração e fiscal, e o inciso $\mathrm{V}$ prevê normas sobre a avaliação de desempenho e a responsabilidade dos administradores, que certamente não se contentarão, dada a índole pública e a vocação estratégica da função social dessas empresas, com as prescrições que a propósito se encontram nas leis das sociedades mercantis, sobretudo voltadas para a satisfação dos interesses dos sócios, e não do interesse público.

É inerente à gênese das empresas públicas e sociedades de economia mista ter compromisso com o interesse público. Ou não seriam, necessariamente, como são, criaturas da lei (art. 37, XIX). A Emenda 19 não rompe o compromisso, que vem desde o Dec.-lei $\mathrm{n}^{0}$ 200/67, como assinalou MANOEL DE OLIVEIRA FRANCO SOBRINHO ao comentar as disposições do art. 28 daquele diploma da primeira reforma administrativa brasileira (entre as quais as de submeter as entidades da administração indireta a prestar contas da sua gestão e a evidenciar os resultados positivos ou negativos de seus trabalhos, "verificando suas causas e justificando as medidas postas em prática ou cuja adoção se impuser, no interesse do Serviço Público" ), in verbis: "a tônica do interesse público está presente no texto e contexto do art. 28. Apesar de pessoas jurídicas autônomas, ... empresas públicas e sociedades de economia mista ficam a dever ao Estado resposta quanto às obrigações cumpridas e por cumprir. Prestar contas da gestão é a regra imperativa. A forma e os prazos fazem as exceções para cada caso. Regidas por leis orgânicas que dão organização à pessoa jurídica e dispõem sobre os órgãos estruturais, nelas as obrigações se fazem na relação jurídica, ou seja, entre o que é da vontade estatal e o que deve ser dever administrativo da entidade" (Comentários à Reforma Administrativa Federal, pág. 122. Ed. Saraiva, 1975).

Vê-se que, nos primórdios da criação dessas entidades pelo direito positivo brasileiro, há mais de três décadas, já se sublinhava, na lei e na doutrina, o seu compromisso com o interesse público. A Emenda 19 nada inova ao reafirmá-lo. A 
questão está em saber se o fato de o compromisso estar agora posto na Constituição terá o efeito de inibir os desvios observados na prática trintenária. E se outra. e renovada. será a visão do que consiste o interesse público na atuação dessas entidades, questão não apenas jurídica, mas também política e econômica. Da Emenda 19 ainda não transparece por inteiro a medida dessa renovação. Espera-se que venha a resultar da lei que aprovará o prometido estatuto jurídico das empresas públicas e sociedades de economia mista, e de suas subsidiárias.

A Emenda 19 faz depender do estatuto o futuro regime jurídico dessas entidades. A norma é de eficácia contida, na expectativa da sobrevinda da lei específica. À falta desta, o regime jurídico das empresas públicas e sociedades de economia mista deve observar a legislação vigente. Entidades que desempenham função social e econômica de relevante interesse público não podem atravessar período de anomia por prazo indeterminado, já que a Emenda sequer o fixou para a promulgação da lei, como fez em relação a outras matérias (v. arts. 27 e 30 da Emenda).

Nada obstante a omissão, a Emenda quer que as entidades da administração indireta revejam seus próprios estatutos individuais no prazo de dois anos da promulgação da Emenda (v. art. 26). Assim, até 5 de junho do ano 2000, todas essas entidades deverão haver concluído o reexame do que os seus estatutos internos estabelecem acerca da natureza jurídica de cada qual, "tendo em conta a finalidade e as competências efetivamente executadas". A ausência da lei federal que aprovará o estatuto jurídico de todas as empresas públicas e sociedades de economia mista não obsta tal revisão, porquanto esta é limitada no seu objeto temporal — ajustamento da natureza jurídica da entidade às competências que venha efetivamente desempenhando, ainda que em desarmonia com os objetivos sociais assentados no ato constitutivo da empresa. É revisão corretiva do descompasso que exista entre a realidade vivenciada pela empresa e a previsão de seus estatutos internos, e não prospectiva quanto ao seu futuro. Deste cuidará o estatuto geral.

A Comissão Especial revisora do Projeto da Emenda, na Câmara dos Deputados, insistiu em que a crítica "de que as expressões 'forma jurídica' e 'regime jurídico' não foram adequadamente substituídas pela expressão 'natureza jurídica' constitui um equívoco... trata-se da natureza jurídica ou privada das instituições, objeto dos estatutos a serem revistos no prazo determinado, e, não, do regime jurídico dos seus servidores".

Quanto às licitações e contratações, de que o estatuto geral também pretende ocupar-se, a solução para evitar a temporária indefinição normativa estará em valerem-se as entidades do permissivo inscrito no art. 119 da Lei $\mathrm{n}^{\mathbf{0}} 8.666 / 93$, e editarem regulamentos próprios, que, não reproduzindo as disposiçōes da lei geral de licitações, já darão cumprimento ao regime delineado pela Emenda 19, estabelecendo regras procedimentais harmonizadas com os princípios licitatórios, com as peculiaridades da estrutura organizacional da empresa e com as características dos serviços que presta ou do mercado em que atua.

Viável a solução porque o mencionado art. 119 não foi recepcionado na íntegra pela Emenda 19. No que, em sua parte final, sujeita os regulamentos internos às disposições da Lei $\mathrm{n}^{\mathrm{o}}$ 8.666/93, o art. 119 passou a conflitar com a redação que a Emenda trouxe para o art. $173, \S I^{\circ}$. III. da Constituição, que remete para a lei, que 
aprovará o estatuto jurídico das empresas públicas e sociedades de economia mista. a disciplina das licitações e contratações de obras, serviços. compras e alienações por essas entidades. Logo, há de considerar-se derrogado o art. 119 nesse aspecto, desde logo liberadas aquelas empresas para a adoção de normas internas que se balizem apenas pelos princípios que presidem as licitações e contratações, e, não, pelas disposições da Lei $\mathrm{n}^{\mathrm{0}}$ 8.666/93.

Nos termos da Emenda 19, passa a ser inequívoco que as para-estatais de segundo grau ou segunda geração, como a doutrina entendeu de rotular as subsidiárias das empresas públicas e sociedades de economia mista, estarão sujeitas ao regime jurídico destas, o que vale dizer que também devem ser consideradas integrantes da administração estatal indireta, sob todas as instâncias de controle interno e externo a que se submetem as matrizes, com funções de idêntica índole, os mesmos direitos, deveres, obrigações e restrições, quer constitucionais (inclusive quanto à vedação de acumulação de cargos, empregos e funções) ou legais (aquelas que o estatuto jurídico vier a estabelecer). 


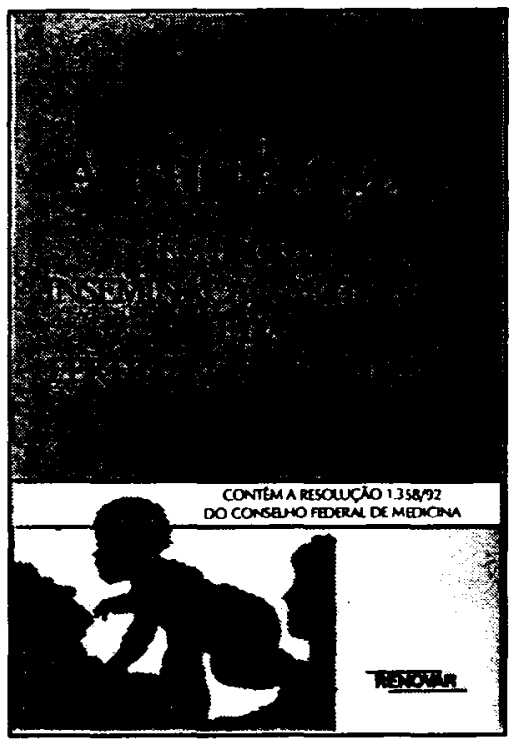

Ref. 0052

Brochura

133 págs.

Form. 14x21

Esgotado

\section{A FILIAÇÃO}

Em Face da Inseminação Artificial e da Fertilização "In Vitro"

\section{Heloisa Helena Barboza}

Trata-se de uma obra de indispensável leitura e que merece profunda meditação, diante do acentuado contraste entre dois fenômenos que vêm cada vez mais adquirindo notoriedade: a morte diária de milhares de crianças, causada pela fome e por doenças as mais simples, e a fabricação, em laboratórios, de outras, em razão dos assustadores progressos da biotecnologia. 